\title{
Terror preparedness as a service of general interest: the Terror and Disaster Surgical Care (TDSC ${ }^{\circledR}$ )-course
}

\author{
Gerhard Achatz ${ }^{1}$. Dan Bieler ${ }^{2,3} \cdot$ Axel Franke $^{2} \cdot$ Benedikt Friemert $^{1} \cdot$ and the Deployment, Disaster and Tactical \\ Surgery Working Group of the German Trauma Society
}

(c) Springer-Verlag GmbH Germany, part of Springer Nature 2020

The threat of terror in Europe is ever present, and the number of attacks worldwide is unfortunately increasing. This means that we must prepare health systems and the corresponding care facilities for treating the victims of such attacks. This necessary task now has political relevance in many countries and can and must be seen as a building block of services of general interest. The severity of injuries after life-threatening situations is a particular challenge for hospitals providing initial care and the staff working in them. The Terror and Disaster Surgical Care (TDSC®)-course is designed to address this challenge. The course was developed and implemented on the basis of an initiative launched in 2016. The aim of the course is to train and support hospital decision-makers in preparation for such scenarios so that they can be mastered in the hospital setting. This "focus-on" issue presents essential information on terror preparedness and basic ideas and concepts of the TDSC®-course.

After a mass casualty incident and especially after terrorist attacks, medical care is a challenge and tactical and strategic aspects must be considered. Friemert et al. impressively illustrate these aspects in their contribution [1]. Terrorist attacks result in a highly dynamic and complex situation in which emergency forces on site-both prehospital

Gerhard Achatz

GerhardAchatz@Bundeswehr.org

http://www.bundeswehrkrankenhaus-ulm.de

1 Department for Trauma Surgery and Orthopaedics, Reconstructive and Septic Surgery, Sportstraumatology, German Armed Forces Hospital Ulm, Oberer Eselsberg 40, 89081 Ulm, Germany

2 Department for Trauma Surgery and Orthopaedics, Reconstructive and Hand Surgery, Burn Medicine, German Armed Forces Central Hospital Koblenz, Rübenacher Straße 170, 56072 Koblenz, Germany

3 Department of Orthopaedics and Trauma Surgery, Heinrich Heine University Hospital, Moorenstraße 5, 40225 Düsseldorf, Germany and in-hospital - are exposed to a high level of danger, the influx of patients into hospitals is uncontrolled and possibly overwhelming, and capacities can quickly reach their limits. Good organisation and preparation is required to deal with an onslaught of highly complex injuries as well as numerous slightly injured patients. The concept of the senior triage coordinator (LArS) as well as the emergency operational and medical coordinator (ZONK) will be presented and explained. Successful internal clinical care in these situations can only be implemented by clear and universally accepted leadership. This means that special treatment concepts, such as Tactical Abbreviated Surgical Care, may have to be applied by the ZONK.

Since the use of weapons of war such as high-energy firearms and bombs can cause warlike injuries and wounds, Bieler et al. explicitly address this topic in their paper [2]. Penetrating injuries accompanied by haemorrhage are not common in Europe, where blunt injuries are more frequently seen. As a result, treatment of penetrating injuries is provided by non-specialist surgeons. This article presents in detail the special nature of gunshot and blast injuries and describes treatment options. The overall tactical and strategic management of mass casualty incidents is also considered.

An important role is played not only by the situation in the hospital and the expected number of patients to be treated but also by appropriate resources, e.g. diagnostic capabilities, blood products, etc. Franke et al. focus on these aspects in their contribution and were able to show that, for example, reduced but focused laboratory diagnostic resources nevertheless allow clinicians to assess the initial severity of a patient's injury and to draw the necessary conclusions about life-saving procedures [3].

In summary, this content is presented and trained in the Terror and Disaster Surgical Care (TDSC®)-course, which was developed by the German Trauma Society (DGU) and the German Armed Forces. Over the course of 2.5 days, the 
course presents important content concerning the special features of terrorist and mass casualty incidents, the associated injury patterns, and tactical and strategic considerations for coping with such situations in hospitals. Important aspects such as CRBN are also highlighted. Bieler et al. discuss this new course format in their paper [4]. The course was implemented in 2017 and had already trained 465 participants by 2019. As a result of these efforts, personnel trained in this field are required for the further certification of hospitals as recognised trauma centres of the TraumaNetwork DGUß.

An important component of the TDSC $®$-course is the table-top exercise, which makes course content tangible. This newly developed board game uses the approach of playful knowledge transfer to ensure the interest, motivation and progress of the target group, namely experienced clinical decision-makers. Players experience relatively abstract procedures and algorithms on an emotional and sensory level and manage and think about critical and complex situations. Course evaluations have shown that participants find this approach target oriented and successful, as the paper by Achatz et al. shows [5].

Finally, the paper by Wurmb et al. in this "focus-on" issue shows as an example the political level of efforts to improve operating conditions in life-threatening situations [6]. It analyses and reviews in detail past terrorist attacks in the context of consensus conferences and presents revised principles and recommendations for future events. It shows that the comprehensive management of such events is highly complex and multi-layered.

The TDSC $®$-course focuses on internal clinical care and organisation during the first hours and interfaces in different directions which have to be considered.

In conclusion, this "focus-on" issue represents a selection of recent efforts made in Germany to provide a service of general interest in the event of terrorist attacks. The main focus here is on the TDSC®-course, which is currently offered in Germany and which focuses primarily on internal clinical care in the first 24 to $48 \mathrm{~h}$ after a terrorist or disaster-related event. The development of an Englishlanguage version has already begun. Establishing the course outside Germany is an important goal. TDSC ${ }^{\circledR}$ can then complement courses that have other priorities, such as the MRMI course. This provides an opportunity to underline the importance of terror preparedness.

We hope that you will enjoy and profit from this issue and that we can initiate and enhance cooperation on this very important topic.

\section{Compliance with ethical standards}

Conflict of interest Achatz G, Bieler D are active as instructors of the TDSC®-course, Friemert B and Franke A are active as directors and instructors of the TDSC $\AA$-course. Achatz G, Bieler D, Franke A and Friemert B developed the TDSC $®$-course concept.

\section{References}

1. Friemert B, Achatz G, Hoth P, et al. Specificities of terrorist attacks: organisation of the in-hospital patient-flow and treatment strategies. Eur J Trauma Emerg Surg. 2020. https://doi. org/10.1007/s00068-020-01390-5.

2. Bieler D, Franke A, Kollig E, et al. Terrorist attacks-common injuries and their initial surgical treatment. Eur J Trauma Emerg Surg. 2020. https://doi.org/10.1007/s00068-020-01342-z.

3. Franke A, Bieler D, Friemert B, et al. Terrorist incidents-strategic treatment objectives, tactical diagnostic procedures, and the estimated need of blood and clotting products. Eur J Trauma Emerg Surg. 2020. https://doi.org/10.1007/s00068-020-01399-w.

4. Bieler D, Franke A, Blätzinger M, et al. Evaluation of the terror and disaster surgical care course. Eur J Trauma Emerg Surg. 2020. https://doi.org/10.1007/s00068-020-01418-w.

5. Achatz G, Friemert B, Trentzsch H, et al. Terror and disaster surgical care-train experienced trauma surgeons in decision making in a MASCAL situation with a table top simulation game. Eur J Trauma Emerg Surg. 2020. https://doi.org/10.1007/s00068-02001441-x.

6. Wurmb T, Franke A, Schorscher N, et al. Emergency response to terrorist attacks - results of the federal conducted evaluation process in Germany. Eur J Trauma Emerg Surg. 2020. https://doi. org/10.1007/s00068-020-01347-8. 